\title{
Aloe vera Inhibits Proliferation of Human Breast and Cervical Cancer Cells and Acts Synergistically with Cisplatin
}

\author{
Arif Hussain $^{1 *}$, Chhavi Sharma ${ }^{1}$, Saniyah Khan ${ }^{1}$, Kruti Shah ${ }^{1}$, Shafiul Haque ${ }^{2}$
}

\begin{abstract}
Many of the anti-cancer agents currently used have an origin in natural sources including plants. Aloe vera is one such plant being studied extensively for its diverse health benefits, including cancer prevention. In this study, the cytotoxic potential of Aloe vera crude extract (ACE) alone or in combination with cisplatin in human breast (MCF-7) and cervical (HeLa) cancer cells was studied by cell viability assay, nuclear morphological examination and cell cycle analysis. Effects were correlated with modulation of expression of genes involved in cell cycle regulation, apoptosis and drug metabolism by RT-PCR. Exposure of cells to ACE resulted in considerable loss of cell viability in a dose- and time-dependent fashion, which was found to be mediated by through the apoptotic pathway as evidenced by changes in the nuclear morphology and the distribution of cells in the different phases of the cell cycle. Interestingly, ACE did not have any significant cytotoxicity towards normal cells, thus placing it in the category of safe chemopreventive agent. Further, the effects were correlated with the downregulation of cyclin D1, CYP 1A1, CYP 1A2 and increased expression of bax and p21 in MCF-7 and HeLa cells. In addition, low dose combination of ACE and cisplatin showed a combination index less than 1, indicating synergistic growth inhibition compared to the agents applied individually. In conclusion, these results signify that Aloe vera may be an effective anti-neoplastic agent to inhibit cancer cell growth and increase the therapeutic efficacy of conventional drugs like cispolatin. Thus promoting the development of plant-derived therapeutic agents appears warranted for novel cancer treatment strategies.
\end{abstract}

Keywords: Aloe vera - bax - cisplatin - cyclin D1 - cytochrome P450 mono-oxygenases - synergistic - p21

Asian Pac J Cancer Prev, 16 (7), 2939-2946

\section{Introduction}

Aloe vera (Aloe barbadensis) is one of the herbal remedies with a longstanding history for its curative and therapeutic properties for various ailments. Till date more than 75 active components with medicinal value have been identified in Aloe vera and have been suggested to possess synergistic action in alleviating the diseased conditions (Scalbert and Williamson, 2000; Hamman, 2008; Nejatzadeh-Barandozi, 2013). Its various biological activities include improving the bioavailability of coadministered vitamins and absorption of poorly absorbable drugs, and also possess purgative, anti-microbial, immunostimulatory, wound healing, anti-inflammatory, anti-tumor, and anti-diabetic activities (Azam et al., 2003; Nejatzadeh-Barandozi, 2013).

Accumulating scientific evidence suggests that Aloe vera possesses remarkable preventive and therapeutic potential against various cancers (Niciforovic et al., 2007; Joseph and Raj, 2010). The bioactive constituents of Aloe vera with chemopreventive potential such as lectin, aloin, barbaloin, aloe-emodin and aloesin have shown to possess immune-potentiating, antimutagenic, anti-proliferative, apoptosis-inducing, anti-oxidant and anti-metastatic potential (Choi and Chung, 2003; Akev et al., 2007; Niciforovic et al., 2007; Joseph and Raj, 2010). The aforementioned activities of Aloe vera (or its constituents) are mediated via targeting various effector molecules such as ER- $\alpha$, STAT3 protein, STAT3-regulated anti-apoptotic (Bcl-xL), MMP-2, urokinase plasminogen activator (u-PA), VEGF receptor (VEGFR) 2, c-Myc, and VEGF (Chen et al., 2010; Huang et al., 2013; Pan et al., 2013). Interestingly, various studies have shown that the prophylactic use of Aloe vera can reduce the intensity of radiation-induced inflammation (Ahmadi, 2012; Haddad et al., 2013). Moreover, the combined use of anticancer agents, especially at low concentrations, and aloe constituents potentiated the growth inhibitory effect of the former on cancer cells (Fenig et al., 2004; Tabolacci et al., 2013).

Aloe vera, due to its multifaceted approach towards targeting cancer cells and less undesirable side effects, may prove to be an agent of choice for treatment of human carcinomas. Therefore, the present study was designed to evaluate the potential of favorable interactions in the novel combination of cisplatin with Aloe vera crude extract 
(ACE), with the aim of potentiating growth inhibition and apoptotic cell death by chemotherapeutic drugs at lower doses and reducing its side effects on normal cells. Additionally these effects of Aloe vera were correlated with the modulation of expression of various genes.

\section{Materials and Methods}

\section{Cancer cell lines}

The effect of ACE alone and in combination with cisplatin was studied on human breast carcinoma cell line (MCF-7) and human cervical carcinoma cell line (HeLa) obtained courtesy of Dr. Tahir Rizvi, UAE University, Al Ain, UAE. The cells were maintained in DMEM supplemented with $10 \% \mathrm{FBS}$, penicillin (100 units/mL), and incubated at $37^{\circ} \mathrm{C}$ in a humidified atmosphere with $5 \% \mathrm{CO}_{2}$. Lymphocytes were isolated from healthy nonsmoking donors using HiSep Media (HiMedia, India) as per the manufacturer's instructions and were maintained in RPMI media (Sigma, USA) (Hussain et al., 2012).

\section{Preparation of drug solutions}

Aloe vera (ACE) was prepared as previously described (Habeeb et al., 2007). Briefly, Aloe vera leaves were washed, dried, and sliced in a longitudinal section and the gel was scraped. The gel was filtered using a sieve and then centrifuged at $350 \mathrm{~g}$ for $50 \mathrm{~min}$. The supernatant was collected in a fresh falcon tube and filtered using 0.2 $\mu \mathrm{m}$ filters. Filtrate was considered to be $100 \%$ extract of Aloe vera and stored at $-20^{\circ} \mathrm{C}$ in aliquots until further use. Further dilutions were made from the stock in complete medium to required concentrations between $1-60 \%$ for the treatment of MCF-7 cells, HeLa cells and lymphocytes. A stock solution of $3.3 \mathrm{mM}$ of cisplatin (Cadila Pharmaceuticals Ltd, India) was used to make drug dilutions of varying concentrations (1-200 $\mu \mathrm{M})$ in complete medium.

\section{Cell viability assay}

The anti-proliferative activity of ACE alone or in combination with cisplatin on MCF-7 cells, HeLa cells and lymphocytes was evaluated using the MTT (3-(4,5-dimethylthiazol-2-yl)-2,5-diphenyltetrazolium bromide) assay, as previously described (Hussain et al., 2012). In short, the cells were plated at a density of $\sim 1 \times 10^{4}$ cells/well in 96-well plates in triplicates. Next day the culture medium was removed and replaced by $200 \mu 1$ of complete culture medium containing 1-60\% concentrations of ACE alone for 24 and 48 h or a combination of ACE $(\mathrm{A} 1=30 \%$ and $\mathrm{A} 2=40 \%)$ with cisplatin $(\mathrm{C} 1=1 \mu \mathrm{M}$ and $\mathrm{C} 2=5 \mu \mathrm{M})$ for $24 \mathrm{~h}$ in 96 -well microtiter plates. After incubation for specified times at $37^{\circ} \mathrm{C}$ in a humidified incubator, MTT ( $5 \mathrm{mg} / \mathrm{ml}$ in PBS) was added to each well and incubated for $2 \mathrm{~h}$. The absorbance was recorded on a microplate reader at the wavelength of $570 \mathrm{~nm}$. The effect of ACE on growth inhibition was assessed as percent cell viability and was calculated as (OD of the drug-treated sample/OD of the non-treated sample) $\times 100$, considering that the colorimetric signal is directly proportional to the number of viable cells. The IC50 (50\% inhibitory concentration) values were calculated from the dose-response curves.

Calculation of Combination effects of cisplatin and ACE

Combination effects were calculated and expressed as a combination index (CI) as previously described (Hussain et al., 2012). CI analysis provides qualitative information on the nature of drug interaction, and CI, a numerical value, was calculated according to the following equation:

$$
\mathrm{CI}=\frac{\mathrm{C}_{\mathrm{A}, \chi}}{\mathrm{IC}_{\chi, \mathrm{A}}}+\frac{\mathrm{X}_{\underline{\mathrm{B}}, \chi}}{\mathrm{IC}_{\chi, \mathrm{B}}}
$$

Where, $\mathrm{CA}, \mathrm{x}$ and $\mathrm{CB}, \mathrm{x}$ are, respectively, the concentrations of drugs $\mathrm{A}$ and $\mathrm{B}$ used in combination to achieve $\mathrm{x} \%$ drug effect. ICx,A and ICx,B are the concentrations for single agents to achieve the same effect. A CI value $<1,=1$, or $>1$ represents, respectively, synergy, additivity, and antagonism of cisplatin and ACE, respectively.

Detection of apoptosis in MCF-7 and HeLa cells after treatment with ACE

Microscopic examination: morphological changes in MCF-7 and HeLa cells were observed on treatment with ACE at different concentrations (40,50 and 60\%) for 24 and $48 \mathrm{~h}$ using a normal inverted microscope (Labomed, USA). The untreated cells were used as negative control.

\section{Nuclear morphological studies}

ACE-induced nuclear morphological changes in MCF7 and HeLa cells were analyzed using propidium iodide staining. Briefly, $\sim 10^{6}$ cells $/ \mathrm{ml}$ cells were seeded on glass coverslips and incubated overnight in complete medium at $37^{\circ} \mathrm{C}$. Further, cells were treated with ACE at its IC50 for a series of time periods $(0,6$ and $24 \mathrm{~h})$. At the end of the desired time interval, cells were fixed in a mixture of acetone: methanol $(1: 1)$ at $-20^{\circ} \mathrm{C}$ for $10 \mathrm{~min}$, washed with $1 \mathrm{X}$ PBS (pH 7.4) twice and stained with propidium iodide $(10 \mathrm{mg} / \mathrm{ml}$ in PBS) for $30 \mathrm{~s}$ in dark at room temperature. The coverslips were thoroughly washed with PBS and placed upturned onto a glass slide with mounting media (DPX). Slides were viewed at $515 \mathrm{~nm}$ under the Progress Fluorescent Microscope (Olympus, USA). The images were captured at $40 \mathrm{X}$ magnification.

\section{Quantification of apoptotic cells by flow cytometry}

ACE-induced apoptosis in MCF-7 and HeLa cells was determined by flow cytometric analysis as described earlier (Hussain et al., 2012). After treatment of synchronous cultures of MCF-7 and HeLa cells with ACE at their respective IC50 for 0 and $24 \mathrm{~h}$, both adherent and floating cells were harvested, washed with phosphate buffered saline (PBS, pH 7.2) and fixed with ice-cold absolute ethanol at $-20^{\circ} \mathrm{C}$ overnight. Cells were then washed with PBS prior to re-suspending in a buffer containing PI (50 $\mathrm{mg} / \mathrm{ml}), 0.1 \%$ sodium citrate, $0.1 \%$ Triton $\mathrm{X}-100$ and 100 $\mathrm{mg} / \mathrm{ml}$ of RNase A. The cells were analyzed using flow cytometry (Beckman Coulter Flow Cytometer FC500, CXP Version 2.2). The data was analyzed using the Beckman Coulter KALUZA 1.1 analysis software. 
Expression analysis of various genes targeted by ACE

Reverse transcription-PCR was used to detect the expression of bax, cyclin D1, p21, CYP 1A1, and CYP $1 \mathrm{~A} 2$ and in response to treatment with ACE at IC50 for varying time points $(0,6$ and $24 \mathrm{~h})$. Total RNA extraction from untreated and ACE-treated MCF-7 and HeLa cells was carried out as per the manufacturer's instructions (GenElute Mammalian Genomic Total RNA Kit, Sigma, USA) at various time intervals. Further, total RNA was subjected to first strand synthesis as per manufacturer's protocol (ProtoScript M-MuLV Taq RT-PCR Kit, New England Biolabs, USA) followed by PCR using genespecific primers (Hussain et al., 2012; Tatemichi et al., 1999; Alao et al., 2004; Wang et al., 2005; Nishimura et al., 2007). $\beta$-actin was taken as an internal control. The PCR cycle was as follows: initial denaturation at $95^{\circ} \mathrm{C}$ for 5 min, followed by 35 amplification cycles (denaturation at $94^{\circ} \mathrm{C}$ for $30 \mathrm{~s}$, annealing at $55^{\circ} \mathrm{C}$ for $\beta$-actin and $\mathrm{p} 21$, $56^{\circ} \mathrm{C}$ for Bax, CYP $1 \mathrm{~A} 1$ and CYP $1 \mathrm{~A} 2$ and $54^{\circ} \mathrm{C}$ for cyclin D1 for $30 \mathrm{~s}$, and extension at $72^{\circ} \mathrm{C}$ for $45 \mathrm{~s}$ ), with final extension at $72^{\circ} \mathrm{C}$ for $7 \mathrm{~min}$. Amplified products were visualized on a $2 \%$ agarose gel containing ethidium bromide.

\section{Statistical analysis}

All data are expressed as means +SD of at least 3 experiments. Fisher's exact test was adopted for statistical evaluation of the results. Significant differences were established at $\mathrm{P}<0.05$.

\section{Results}

ACE shows selective cytotoxic effects towards MCF-7 and HeLa cells

The growth inhibitory effects of different concentrations of ACE on MCF-7 cells, HeLa cells and lymphocytes were assessed by the MTT assay. MCF-7 and HeLa cells treated with increasing concentrations of ACE ranging from 1\%$60 \%$ for 24 and $48 \mathrm{~h}$ showed a dose and time-dependent increase in cell death (Figure $1 \mathrm{~A}$ and B). The IC50 was found to be at $60 \%$ after $24 \mathrm{~h}$ treatment with ACE in both the cell lines (Figure $1 \mathrm{~A}$ and $\mathrm{B}$ ).

In order to determine whether ACE shows selective toxicity, lymphocytes were treated with similar doses (1\%-60\%) of ACE. No significant cytotoxic effect on cell viability was observed after the treatment with ACE for $24 \mathrm{~h}$ at the above mentioned concentrations (Figure 1C), thereby supporting the safe toxic profile of ACE.

\section{ACE induces cell death via apoptosis in MCF-7 \& HeLa cells}

Morphological examinations of MCF-7 \& HeLa Cells: Morphological characteristics of ACE treated MCF-7 (40\%, 50\% and 60\%) \& HeLa cells $(30 \%, 40 \%$ and $60 \%$ ) were visualized by using inverted microscope for 24 and $48 \mathrm{~h}$ respectively. In comparison to untreated, ACE treated cells showed typical features of cell death at the morphological level such as rounding off of cells, cell shrinkage and detachment from the substrate which accumulated in a dose and time-dependent manner, thus indicating that ACE induces cell death by apoptosis in these cells (Figure $2 \mathrm{~A}$ and $\mathrm{B}$ ).

\section{Aloe vera induced nuclear morphological changes in MCF-7 \& HeLa Cells}

ACE induced nuclear morphological changes characteristic of typical cell undergoing apoptosis were studied in MCF-7 and HeLa cells at their respective IC50 at various time-points. Untreated MCF-7 and HeLa cells appeared uniform in chromatin density with an intact nucleus (yellow arrows). However, on treatment of MCF-7 cells with ACE for 6 and $24 \mathrm{~h}$ resulted in
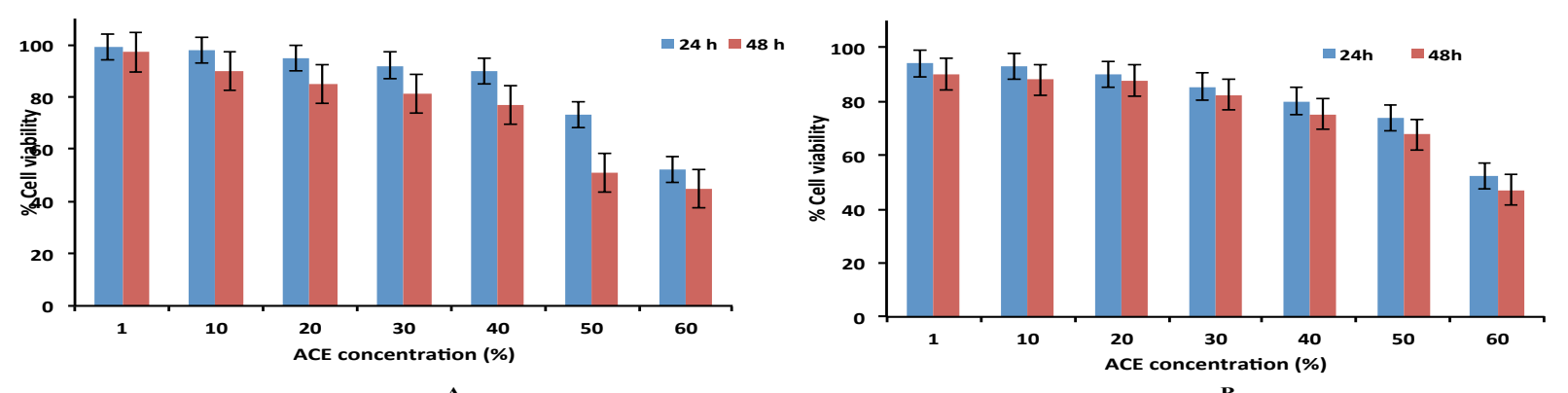

$\mathbf{A}$

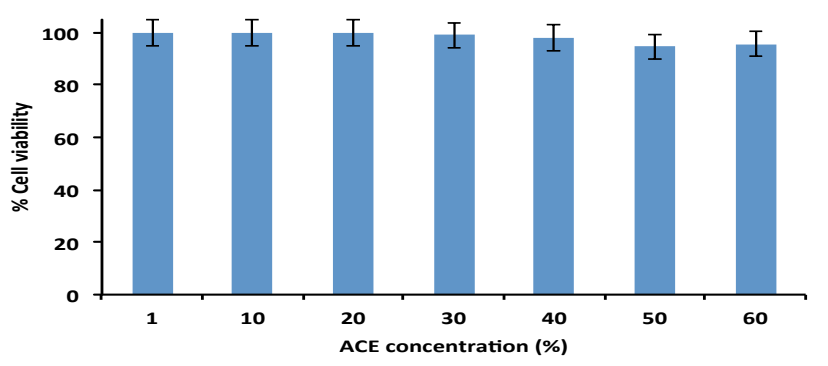

Figure 1. Differential Cytotoxicity of ACE on MCF-7 and HeLa Cells. (A \& B) MCF-7 and HeLa cells treated with $\mathrm{ACE}$ at varying concentrations (1-60\%) results in dose and time dependent growth inhibition after 24 and $48 \mathrm{~h}$ treatment whereas treatment of lymphocytes with ACE at similar concentrations for $24 \mathrm{~h}$ was found to be minimally cytotoxic (C). Values are means $+\mathrm{SD}$ of three independent experiments. Each value with ACE treatment differs from the control value $(\mathrm{p}<0.05)$ 

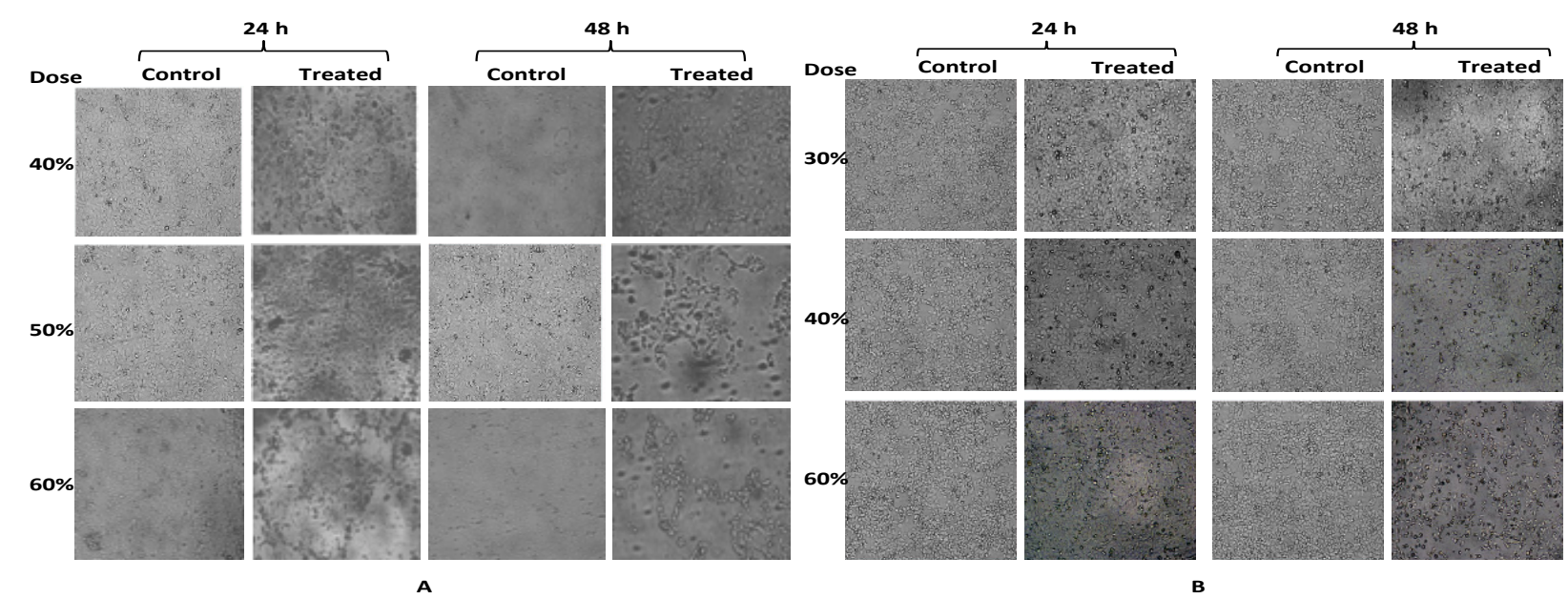

Figure 2. ACE treatment of MCF-7 (A) and HeLa cells (B) at Varying Concentrations Result in Morphological Changes Typically Associated with Apoptosis. ACE treatment of MCF-7 (at 40,50 and $60 \%$ for 24 and 48 h) (A) and HeLa (at 40,50 and $60 \%$ for 24 and 48 h) (B) cells result in characteristic rounding off and substrate detachment of these cells compared to untreated cells which accumulated with increase in dose and time of ACE treatment. (Magnification 100X)
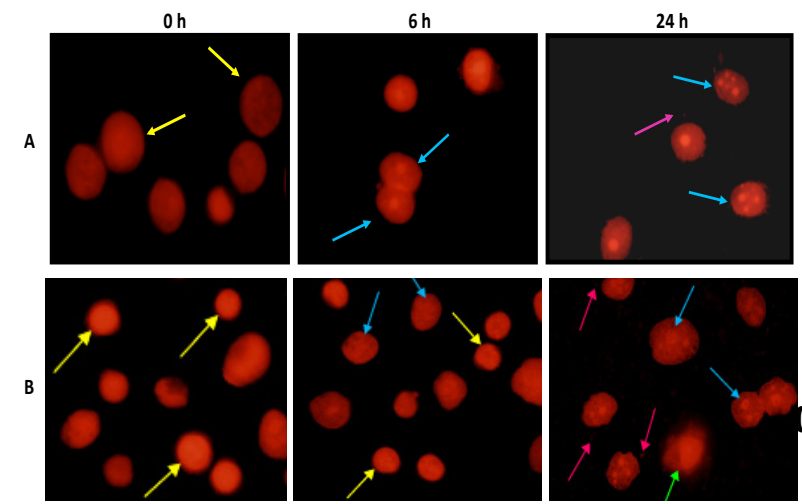

Figure 3. Treatment of MCF-7 (A) and HeLa (B) Cells with $\mathrm{ACE}$ at Various Time Intervals $(0,6$ and 24 h) Induce Characteristic Nuclear Morphological Changes Linked with Apoptosis. Untreated MCF-7 and HeLa cells $(0 \mathrm{~h})$ show large and prominent nuclei indicating no significant characteristics of apoptosis (yellow arrows). MCF7 (A) and HeLa (B) cells treated with ACE at their respective EC50 for 6 and $24 \mathrm{~h}$ showed time- dependent increase in nuclear morphological changes associated with apoptosis such as nuclear condensation and fragmentation (blue arrows), nuclear blebbing (green arrows) and apoptotic bodies (pink arrows). (Magnification 400X)

apoptosis-associated nuclear morphological changes like chromatin condensation and fragmentation (blue arrows) along with appearance of apoptotic bodies (pink arrows) (Figure 3A). Also, HeLa cells treated with ACE showed similar changes in nuclear morphology including blebbing (green arrow) (Figure 3B). With an increase in duration of ACE exposure, there was a cumulative accrual of the said features consistent with apoptosis in both the cell lines (Figure $3 \mathrm{~A}$ and $\mathrm{B}$ ).

\section{Cell cycle analysis of MCF-7 \& HeLa cells}

Cell cycle distribution of MCF-7 and HeLa cells was determined by flow cytometry after the treatment of these cells with ACE at their respective EC50 concentrations for $24 \mathrm{~h}$. Cell cycle analysis demonstrated that $60 \% \mathrm{ACE}$ treated MCF-7 \& HeLa show increased number of cells

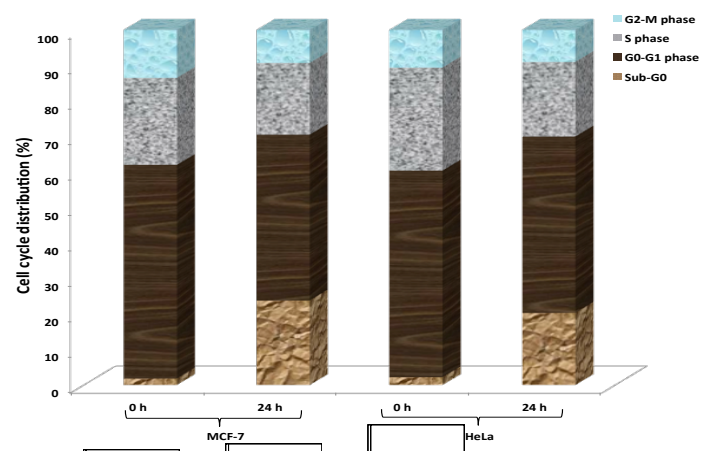

Figure 4. Cell Cycle Analysis of ACE Treated MCF-7 and HeLa Cells by Flow Cytometry. MCF-7 and HeLa cells treated with ACE at their respective EC50 doses for $24 \mathrm{~h}$ showed a significant decrease in the proportion of cells in the sub-G0/G1 phase of the cell cycle indicating that ACE treatment results in apoptosis in these cells in comparison to untreated cells with normal distribution of cells in various phases of cell cycle. The histogram shows \% analysis of cells in the different phases of the cell cycle from a representative experiment (out of three individual experiments)

in sub G0/G1 phase with an associated decrease in the number of cells in S-phase and G2-phase of the cell cycle when compared to the untreated control. The untreated cells $(0 \mathrm{~h})$ showed appropriate distribution of cells in the different phases of cell cycle (Figure 4); while in case of ACE treated cells, there was a significant time-dependent increase in the number of cells in the sub-G0\G1 phase of the cell cycle. This confirms that ACE induces the cell death via apoptosis.

ACE treatment significantly modulates the expression of cyclin D1, bax, CYP 1A1, CYP 1A2 and p21

With the target of determining the effector genes involved in ACE mediated cellular responses in MCF-7 and HeLa cells, the expression of cyclin D1, bax, CYP 1A1, CYP 1A2 and p21 were analyzed before and after treatment with ACE at 6 and $24 \mathrm{~h}$ respectively. $\beta$-actin was used as an internal control for comparison of samples.

The aberrant expression of cyclin D1, a key player 
in the progression of the cells from $\mathrm{G} 1$ to $\mathrm{S}$ phase, has been associated with the deregulated cell cycle control in many human cancers. It was found to be over-expressed in both the untreated MCF-7 and HeLa cells (Figure $5 \mathrm{~A}$ and $\mathrm{B}$ ). As shown in Figure $5 \mathrm{~A}$ and $\mathrm{B}$, a significant, timedependent inhibitory effect of ACE was observed on the expression of cyclin D1 in both the cell lines compared to untreated cells.

Bax, the first identified pro-apoptotic member of the Bcl-2 protein family, plays a major role in inducing apoptosis. In both untreated MCF-7 and HeLa cells, the expression of bax was found to be low which significantly increased in ACE treated MCF-7 and HeLa cells in a time-dependent manner in comparison to the untreated cells (Figure $5 \mathrm{~A}$ and B).

Progression through the cell cycle is regulated through activation and inactivation of cyclin-dependent kinase (Cdks) that form sequential complexes with cyclins A-E during the different phases G1, S, G2, and M of the cell cycle. The activity of Cdks is controlled by binding of Cdk inhibitors (CKIs) to Cdk-cyclin complexes. One such CKIs is p21, preferentially interact with Cdk2- and Cdk4-cyclin complexes and block their interaction with cyclin D and thus functions as a regulator of cell cycle progression at G1. In both untreated MCF-7 and HeLa cells, the expression of p21 was found to be low which significantly increased in ACE treated MCF-7 and HeLa cells in a time-dependent manner in comparison to the untreated cells (Figure $5 \mathrm{~A}$ and $\mathrm{B}$ ).

CYP $1 \mathrm{~A} 1$ and CYP $1 \mathrm{~A} 2$ are the members of the cytochrome P450 enzyme superfamily, which act as drug metabolizing enzymes and leads to the accumulation reactive oxygen species forming ultimate carcinogens that are toxic to the cell and thereby leading to tumorigenesis. Expression of CYPA1 and CYPA2 was detected in untreated MCF-7 and HeLa cells (Figure $5 \mathrm{~A}$ and B). However, in comparison to the untreated cells, ACE treatment resulted in significant downregulation of these genes in both the cancer cell lines (Figure $5 \mathrm{~A}$ and B).

ACE and cisplatin infusion act synergistically to inhibit the growth of MCF-7 and HeLa cells

Since currently available chemotherapeutic drugs are associated with non-specific cytotoxicity towards normal cells as well as development of chemo-resistance, a combinational treatment with the natural dietary agents may serve as a better approach towards cancer treatment. In the present study, a combination of ACE and cisplatin was evaluated to potentiate the chemotherapeutic index of cisplatin.

The effect of concurrent treatment of MCF-7 and HeLa cells with different sub-lethal concentrations of cisplatin and ACE for $24 \mathrm{~h}$ was analyzed by cell viability assay. It was observed that $1 \mu \mathrm{M}$ of cisplatin $(\mathrm{C} 1)$ used in combination with $30 \%$ (A1) and 40\% (A2) ACE resulted in a significant decrease in cell viability (81 and $71 \%$ respectively) of MCF-7 cells as compared to either of the compounds alone (98.2\% for $\mathrm{C} 1,92$ and $90 \%$ for $\mathrm{A} 1$ and A2) (Figure $6 \mathrm{~A}$ ). In HeLa cells, the combination of $1 \mu \mathrm{M}$ of cisplatin (C1) with $30 \%$ (A1) and $40 \%$ (A2) ACE resulted in 75 and $60 \%$ (for $\mathrm{C} 1 \mathrm{~A} 1$ and $\mathrm{C} 1 \mathrm{~A} 2$ ) significant

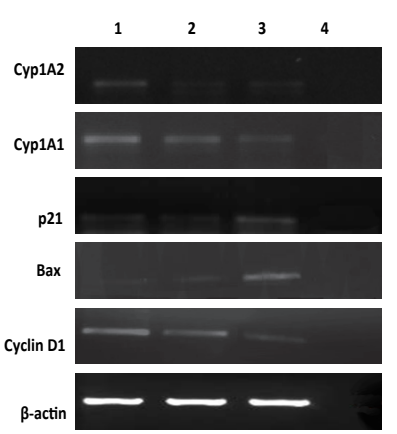

MCF-7

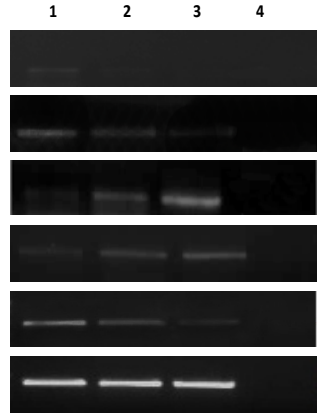

HeLa
Figure 5. ACE Targeted Modulation of Various Genes. ACE treated MCF-7 (A) and HeLa (B) cells at their respective EC50 doses for 6 and $24 \mathrm{~h}$ show a significant decrease in the expression of cyclin D1, CYP1A1 an CYP1A2 while a significant up-regulation in the expression of bax and p21 in a time-dependent manner compared to untreated cells. $\beta$-Actin was used as an internal control. Lanes 1-4 represent untreated cells, cells treated with ACE for 6 and $24 \mathrm{~h}$, and negative control for RT-PCR respectively

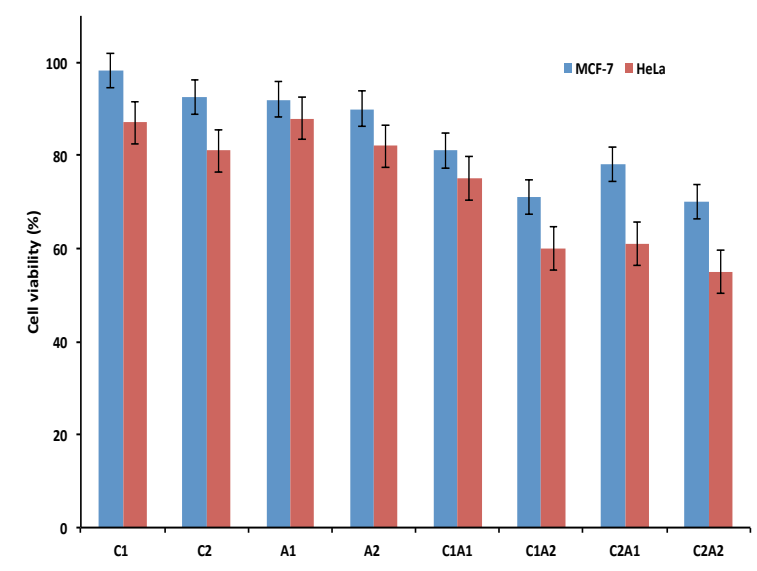

Figure 6. Concomitant Treatment of MCF-7 and HeLa Cells with Sub-lethal doses of ACE (A1 and A2) and Cisplatin (C1 and C2) was found to Induce Synergistic Decrease in Cell Viability in these Cells (Combination Index $(\mathbf{C I}<\mathbf{1})$. Each value is a ratio of the level in the treated cells to that in the untreated control cells. Values are means \pm $\mathrm{SD}$ of 3 independent experiments. Each value with cisplatin and ACE treatment differs from the control value $(\mathrm{p}<.05)$

decrease in cell viability while individual drugs decreased the cell viability by $84 \%$ for $\mathrm{C} 1$ and 88 and $82 \%$ with $\mathrm{A} 1$ and $\mathrm{A} 2$ respectively (Figure $6 \mathrm{~B}$ ). Also, treatment of $\mathrm{MCF}$ 7 and HeLa cells with $5 \mu \mathrm{M}$ of cisplatin (C2) combined with $\mathrm{A} 1$ and $\mathrm{A} 2$ respectively resulted in synergistic decrease in cell viability (78 and $70 \%$ for MCF-7; 61 and $55 \%$ for HeLa) as compared to individual doses (C2 $=92.5 \%$ and $81 \%$ for MCF-7 and HeLa) (Figure $6 \mathrm{~A}$ and B). Combinational indices (CI) were calculated and CI less than 1 were found to be less than 1 indicating a synergistic interaction between the two drugs at the doses used for both MCF-7 and HeLa cells.

\section{Discussion}

The recent goal of cancer treatment is to reverse, suppress, or prevent carcinogenic progression through 
the use of natural dietary agents (Oyagbemi et al., 2009; Kundu and Chun, 2014; Thumvijit et al., 2014). With this perspective, the present study was designed to utilize the anti-carcinogenic potential of Aloe vera, one of the oldest medicinal plants used extensively for its health benefits, including cancer prevention. Due to its tumor-inhibitory effect in vitro and in vivo and its ability to minimize the various side effects caused by conventional therapy including chemotherapy, Aloe vera has gained significant attention for providing new prospects for the development of novel therapeutics. The most important substances that make up the aloe are cinnamic acid, barbalonia, resistanolo oil, calcium and aloin (Kuo et al., 2002; Esmat et al., 2005; Guo et al., 2008; Niciforovic et al., 2007; Chou and Liang, 2009).

In the present study it was observed that treatment of MCF-7 and HeLa cells with ACE at varying doses $1 \%-60 \%$ for 24 and $48 \mathrm{~h}$ decreased the viability of these cells in a dose and time dependent manner (Figure $1 \mathrm{~A}$ and B). On the contrary, there was no significant decrease in the viability of normal lymphocytes when treated with ACE at similar doses (Figure $1 \mathrm{C}$ ). These results are in accordance with previous studies which demonstrated that Aloe vera extract or its components significantly reduced proliferation of cancer cells in vitro and in vivo while being less toxic towards the normal cells (Kuo et al., 2002; Shimpo et al., 2003; Shieh et al., 2004; Guo et al., 2008; Xiao and Guo, 2009; Chandu et al., 2012).

Since necrosis is often associated with an intense inflammatory response to surrounding tissue, apoptosis is the desirable mode of cell death by therapeutic drugs used in cancer treatment. Considering this fact, the cellular and nuclear morphological changes induced by ACE treatment in MCF-7 and HeLa cells were analyzed (Figure 2 and 3). It was observed that treatment of MCF-7 and HeLa cells with ACE resulted in significant changes in cellular morphology in a time and dose dependent manner characterized with rounding off of the cells, cell shrinkage and detachment from the matrix (Figure $2 \mathrm{~A}$ and B). At nuclear level, chromatin condensation and fragmentation along with appearance of apoptotic bodies intensified with increasing time of exposure of ACE (at EC50 doses) in both the cell lines in comparison to the untreated cells in which these changes were lacking indicating that cell death induced by AWE is through apoptotic pathway (Figure $3 \mathrm{~A}$ and B). Cell cycle analysis revealed a significantly increased proportion of cells in the sub-G0/G1 phase on treatment with ACE at EC50 dose while the untreated cells showed appropriate distribution of cells in the different phases of cell cycle (Figure 4). This confirms that ACE induces the cell death via apoptosis. Various other studies have also confirmed that the different constituents of Aloe vera induce cell cycle arrest and apoptosis in cancer cells (Jeon et al., 2012; Suboj et al., 2012; Huang et al., 2013; Ismail et al., 2013; Pan et al., 2013).

These anti-proliferative and apoptosis-inducing effects of Aloe vera were correlated with the expression of genes involved in these mechanisms such as bax, p21 and cyclin D1. Bax, a pro-apoptotic member of the bcl-2 family, its downregulation has been linked with evasion of apoptosis in cancer cells and is involved in mediating the response to a wide range of cytotoxic stimuli (Kagawa et al., 2000; Cuddeback et al., 2001). It was found that treatment of MCF-7 and HeLa cells with ACE resulted in increased expression of bax gene in a time dependent manner in comparison to untreated cells which showed very low expression of bax gene in both the cell lines (Figure 5). Thus, the downregulation of bax in these cells may be responsible in part for the apoptosis-inducing effects of Aloe vera. Various chemopreventive agents including Aloe vera constituents have been shown to induce apoptosis via up regulation of bax (Kuo et al., 2002; Chiu et al., 2009; Lin et al., 2010; Tomasin and Gomes-Marcondes, 2011; Chung et al., 2013; Li et al., 2013).

The anti-proliferative activity induced by Aloe vera in MCF-7 and HeLa cells was found to be linked with the expression of cyclin D1 and p21 (Figure 5). Cyclin D1, a proto-oncogene, is a key regulator of cell cycle and its aberrant expression has been associated with development and progression of several cancers (Alao, 2007; Musgrove et al., 2011; Stone et al., 2012). It can function as a transcriptional co-regulator in conjunction with its binding partners including p21, a cyclin-dependent kinase (cdk) inhibitor, which induces cell cycle arrest and is found to contribute to cancer preventive effect of certain dietary agents such as aloe-emodin, ellagic acid and zinc (Kuo et al., 2002; Chung et al., 2013; Yang et al., 2013). In the present study it was observed that ACE treated MCF-7 and HeLa cells showed time-dependent decrease in the expression of cyclin D1 in comparison to the untreated cells which showed high expression of this gene (Figure 5). Further, the untreated cells showed low expression of p21 which was found to increase in a time-dependent manner when treated with ACE (Figure 5).

Another important gene family member, CYP $1 \mathrm{~A} 1$ and and CYP 1A2 which are key players in phase I-dependent metabolism of drugs and other xenobiotics that often exert toxicity or carcinogenicity and thus modulation of their expression may be significant determinant of cancer therapy (Androutsopoulos et al., 2009; Kavitha et al., 2013; Kim et al., 2013; Jeena et al., 2014). Our results showed that ACE treatment of MCF-7 and HeLa cells induced substantial loss in the expression of CYP1A1 and CYP1A2 genes as the duration of treatment increased as compared to the untreated HeLa which had a higher expression of these genes (Figure 5). Increases in their expression have been linked to a higher risk of malignancies (Androutsopoulos et al., 2009). Chemopreventive agents including aloe constituents have been previously shown to modulate the expression of CYP genes including CYP1A1 and CYP1A2 (Tang et al., 2009; Kavitha et al., 2013; Kim et al., 2013; Jeena et al., 2014)

The emergence of resistant cells to chemotherapeutic agents, referred to as chemoresitance is one of the major problems of conventional cancer therapy necessitating the need to develop newer approaches for cancer prevention and treatment (Mijatovic et al., 2005; Sasabe et al., 2007). Therefore the combinatorial chemopreventive approach was carried out to hit more than one molecular target with the simultaneous treatment of Aloe vera and a chemotherapeutic drug, cisplatin to enhance the therapeutic index at low-dose combinations. It was found 
that cisplatin had nonspecific cytotoxicity towards both the cancer cell lines (MCF-7 and HeLa cells) along with the normal cells (data not shown). It was observed that sublethal doses of $\mathrm{ACE}$ and cisplatin in various combinations (C1A1, C1A2, C2A1 and C2A2 for MCF-7 and HeLa cells) showed significantly increased growth inhibition of these cells in comparison to the individual doses as reflected in the CI less than 1 indicating a synergistic interaction between these drugs at the doses used (Figure $6)$. These results are in line with other studies which showed that a synergistic effect of concurrent use of chemopreventive agents with other cancer therapeutic agents (Fenig et al., 2004; Mijatovic et al., 2005; Zeng et al., 2008; Lissoni et al., 2009; Tabolacci et al., 2013). Interestingly, a previous study correlated increased expression of bax with chemosensitivity of breast cancer cells towards chemotherapy (Sakakura et al., 1997). As discussed above, the overexpression of bax, induced by Aloe vera may be linked with its chemo-potentiating effect in these cells.

In conclusion Aloe vera alone or its simultaneous use with cisplatin exhibits anti-neoplastic effects in breast and cervical cancers by inducing apoptosis and modulation of expression of effector molecules. Thereby, this study provides a rationale for future experiments that will shed new lights on the underlying mechanisms or potential targets of Aloe vera for its better utilization as anticancer agents.

\section{Acknowledgements}

Authors are grateful to Dr. Kota Reddy, Academic President and Dr. Firdos Alam Khan, Chairperson, School of Life Sciences, Manipal University, Dubai for their constant support. Also, the authors would like to extend their thanks to Dr. Tahir Rizvi, UAE University, Al-Ain, UAE for providing HeLa cells which were used in this study.

\section{References}

Ahmadi A (2012). Potential prevention: Aloe vera mouthwash may reduce radiation-induced oral mucositis in head and neck cancer patients. Chin J Integr Med, 18, 635-40.

Akev N, Turkay G, Can A, et al (2007). Tumour preventive effect of Aloe vera leaf pulp lectin (Aloctin I) on Ehrlich ascites tumours in mice. Phytother Res, 21, 1070-5.

Alao JP (2007). The regulation of cyclin D1 degradation: roles in cancer development and the potential for therapeutic invention. Molecular Cancer, 6, 24.

Alao JP, Lam EW, Ali S, et al (2004). Histone deacetylase inhibitor trichostatin A represses estrogen receptor alpha-dependent transcription and promotes proteasomal degradation of cyclin D1 in human breast carcinoma cell lines. Clin Cancer Res, 10, 8094-104.

Androutsopoulos VP, Tsatsakis AM, Spandidos DA (2009). BMC Cytochrome P450 CYP1A1: wider roles in cancer progression and prevention. BMC Cancer, 16, 187.

Atul NC, Santhosh CK, Chiranjib B, Subal D (2012). Cytotoxicity study of plant Aloe vera, (Linn). Chronicles Young Scientist, 3, 233-35.

Azam S, Hadi N, Khan NU, Hadi SM (2003). Antioxidant and prooxidant properties of caffeine, theobromine and xanthine.
Med Sci Monit, 3, 325-30.

Chen YY, Chiang SY, Lin JG, et al (2010). Emodin, aloe-emodin and rhein inhibit migration and invasion in human tongue cancer SCC-4 cells through the inhibition of gene expression of matrix metalloproteinase-9. Int J Oncol, 36, 1113-20.

Chiu TH, Lai WW, Hsia TC, et al (2009). Aloe-emodin induces cell death through S-phase arrest and caspase-dependent pathways in human tongue squamous cancer SCC-4 cells. Anticancer Res, 29, 4503-11.

Choi S, Chung, MH (2003). A review on the relationship between Aloe vera components and their biologic effects. Semin Integr Med, 1, 53-62.

Chou TH, Liang CH (2009). The molecular effects of aloeemodin (AE)/liposome-AE on human nonmelanoma skin cancer cells and skin permeation. Chem Res Toxicol, 22, 2017-28.

Chung YC, Lu LC, Tsai MH, et al (2013). The inhibitory effect of ellagic Acid on cell growth of ovarian carcinoma cells. Evid Based Complement Alternat Med, 2013, 306705.

Cuddeback SM, Yamaguchi H, Komatsu K, et al (2001). Molecular cloning and characterization of Bif-1. A novel Src homology 3 domain-containing protein that associates with Bax. J Biol Chem, 276, 20559-65.

Elizabeth A, Musgrove C, Elizabeth Caldon, et al (2011). Cyclin $\mathrm{D}$ as a therapeutic target in cancer. Nature Reviews Cancer, 1, 558-72.

Esmat AY, El-Gerzawy SM, Rafaat A (2005). DNA ploidy and $S$ phase fraction of breast and ovarian tumor cells treated with a natural anthracycline analog (aloin). Cancer Biol Ther, 4, 108-12.

Fenig E, Nordenberg J, Beery E, Sulkes J, Wasserman L (2004). Combined effect of aloe-emodin and chemotherapeutic agents on the proliferation of an adherent variant cell line of Merkel cell carcinoma. Oncol Rep, 11, 213-7.

Guo J, Xiao B, Liu Q, Gong Z, Le Y (2008). Suppression of $\mathrm{C}$-myc expression associates with anti-proliferation of aloeemodin on gastric cancer cells. Cancer Invest, 26, 369-74.

Habeeb F, Shakir E, Bradbury F, et al (2007). Screening methods used to determine the anti-microbial properties of Aloe vera inner gel. Methods, 42, 315-320.

Haddad P, Amouzgar-Hashemi F, Samsami S, Chinichian S, Oghabian MA (2013). Aloe vera for prevention of radiationinduced dermatitis: a self-controlled clinical trial. Curr Oncol, 20, 345-8.

Hamman JH (2008). Composition and applications of Aloe vera leaf gel. Molecules, 3, 1599-616.

Huang PH, Huang CY, Chen MC, et al (2013). Emodin and Aloe-Emodin Suppress Breast Cancer Cell Proliferation through ER $\alpha$ Inhibition. Evid Based Complement Alternat Med, 2013, 376123.

Hussain A, Priyani A, Sadrieh L, Brahmbhatt K, Ahmed M, Sharma C (2012). Concurrent sulforaphane and eugenol induces differential effects on human cervical cancer cells. Integr Cancer Ther, 11, 154-65.

Ismail S, Haris K, Abdul Ghani ARet al (2013). Enhanced induction of cell cycle arrest and apoptosis via the mitochondrial membrane potential disruption in human U87 malignant glioma cells by aloe emodin. J Asian Nat Prod Res, 2013.

Jeena K, Liju VB, Viswanathan R, Kuttan R (2014). Antimutagenic potential and modulation of carcinogenmetabolizing enzymes by ginger essential oil. Phytother Res Phytother Res, 28, 849-55.

Jeon W, Jeon YK, Nam MJ (2012). Apoptosis by aloe-emodin is mediated through down-regulation of calpain-2 and ubiquitin-protein ligase E3A in human hepatoma Huh-7 cells. Cell Biol Int, 36, 163-7. 


\section{Arif Hussain et al}

Joseph B, SJ Raj (2010). Pharmacognostic and phytochemical properties of Aleo vera Linn: An overview. Int J Pharma Sci Rev Res, 4, 106-110.

Kagawa S, Gu J, Swisher SG, et al (2000). Antitumor effect of adenovirus-mediated Bax gene transfer on $\mathrm{p} 53$-sensitive and p53-resistant cancer lines. Cancer Res, 60, 1157-61.

Kavitha K, Thiyagarajan P, Rathna Nandhini J, Mishra R, Nagini S (2013). Chemopreventive effects of diverse dietary phytochemicals against DMBA-induced hamster buccal pouch carcinogenesis via the induction of Nrf2-mediated cytoprotective antioxidant, detoxification, and DNA repair enzymes. Biochimie, 95, 1629-39.

Kim IS, Kim Y, Kwak TH, Yoo HH (2013). Effects of $\beta$-lapachone, a new anticancer candidate, on cytochrome P450-mediated drug metabolism. Cancer Chemother Pharmacol, 72, 699-702.

Kundu JK, Chun KS (2014). The promise of dried fruits in cancer chemoprevention. Asian Pac J Cancer Prev, 15, 3343-52.

Kuo PL, Lin TC, Lin CC (2002). The antiproliferative activity of aloe-emodin is through p53-dependent and p21-dependent apoptotic pathway in human hepatoma cell lines. Life Sci, 71, 1879-92.

Li Q, Zhou S, Jing J, et al (2013). Oligosaccharide from apple induces apoptosis and cell cycle arrest in HT29 human colon cancer cells. Int J Biol Macromol, 57, 245-54.

Lin ML, Lu YC, Chung JG, et al (2010). Aloe-emodin induces apoptosis of human nasopharyngeal carcinoma cells via caspase-8-mediated activation of the mitochondrial death pathway. Cancer Lett, 291, 46-58

Lissoni P, Rovelli F, Brivio F, et al (2009). A randomized study of chemotherapy versus biochemotherapy with chemotherapy plus Aloe arborescens in patients with metastatic cancer. In vivo, 23, 171-5.

Mijatovic S, Maksimovic-Ivanic D, Radovic J, et al (2005). Aloe emodin decreases the ERK-dependent anticancer activity of cisplatin. Cell Mol Life Sci, 62, 1275-82.

Nejatzadeh-Barandozi F (2013). Antibacterial activities and antioxidant capacity of Aloe vera. Org Med Chem Lett, 3,5 .

Niciforovic A, Adzic M, Spasic SD, Radojcic MB (2007). Antitumor effects of a natural anthracycline analog (Aloin) involve altered activity of antioxidant enzymes in HeLaS3 cells. Cancer Biol Ther, 6, 1200-5.

Nishimura M, Koeda A, Suganuma Y, et al (2007). Comparison of inducibility of CYP1A and CYP3A mRNAs by prototypical inducers in primary cultures of human, cynomolgus monkey, and rat hepatocytes. Drug Metab Pharmacokinet, 22, 178-86.

Oyagbemi AA, Azeez OI, Saba AB (2009). Interactions between reactive oxygen species and cancer: the roles of natural dietary antioxidants and their molecular mechanisms of action. Asian Pac J Cancer Prev, 10, 535-44.

Pan Q, Pan H, Lou H, Xu Y (2013). Inhibition of the angiogenesis and growth of Aloin in human colorectal cancer in vitro and in vivo. Cancer Cell Int, 13, 69.

Sakakura C, Sweeney EA, Shirahama T, et al (1997). Overexpression of bax sensitizes breast cancer MCF-7 cells to cisplatin and etoposide. Surg Today, 27, 676-9.

Sasabe E, Zhou X, Li D, et al (2007). The involvement of hypoxia-inducible factor-1alpha in the susceptibility to gamma-rays and chemotherapeutic drugs of oral squamous cell carcinoma cells. Int J Cancer, 120, 268-77.

Scalbert A, Williamson D (2000). Dietary intake and bioavailability of polyphenols. J Nutr, 3, 2073-85.

Shieh DE, Chen YY, Yen MH, Chiang LC, Lin CC (2004). Emodin-induced apoptosis through p53-dependent pathway in human hepatoma cells. Life Sci, 74, 2279-90.

Shimpo K, Chihara T, Beppu H, et al (2003). Inhibition of azoxymethane-induced DNA adduct formation by Aloe arborescens var. natalensis. Asian Pac J Cancer Prev, 4, 247-51.

Stone A, Sutherland RL, Musgrove EA (2012). Inhibitors of cell cycle kinases: recent advances and future prospects as cancer therapeutics. Crit Rev Oncog, 7, 175-98.

Suboj P, Babykutty S, Srinivas P, Gopala S (2012). Aloe emodin induces $\mathrm{G} 2 / \mathrm{M}$ cell cycle arrest and apoptosis via activation of caspase-6 in human colon cancer cells. Pharmacology, 89, 91-8.

Tabolacci C1, Rossi S, Lentini A, et al (2013). Aloin enhances cisplatin antineoplastic activity in B16-F10 melanoma cells by transglutaminase-induced differentiation. Amino Acids, 44, 293-300.

Tang JC, Yang H, Song XY, et al (2009). Inhibition of cytochrome P450 enzymes by rhein in rat liver microsomes. Phytother Res, 23, 159-64.

Tatemichi M, Nomura S, Ogura T, et al (1999). Mutagenic activation of environmental carcinogens by microsomes of gastric mucosa with intestinal Metaplasia. Cancer Res, 59, 3893-8.

Thumvijit T, Taya S, Punvittayagul C, Peerapornpisal Y, Wongpoomchai R (2014). Cancer chemopreventive effect of Spirogyra neglecta (Hassall) Kutzing on diethylnitrosamineinduced hepatocarcinogenesis in rats. Asian Pac J Cancer Prev, 15, 1611-6.

Tomasin R, Gomes-Marcondes MC (2011). Oral administration of Aloe vera and honey reduces Walker tumour growth by decreasing cell proliferation and increasing apoptosis in tumour tissue. Phytother Res, 25, 619-23.

Wang AG, Kim SU, Lee SH, Kim SK, Seo SB, Yu DY, Lee DS (2005). Histone deacetylase 1 contributes to cell cycle and apoptosis. Biol Pharm Bull, 28, 1966-70.

Xiao BX, Guo J (2009). The anti-proliferation and anti-migration dual effects of aloe-emodin on KB cells and its mechanism. Zhonghua Kou Qiang Yi Xue Za Zhi, 44, 50-2.

Yang N, Zhao B, Rasul A, Qin H, Li J, Li X (2013). PIAS1modulated Smad2/4 complex activation is involved in zinc-induced cancer cell apoptosis. Cell Death Dis, 19, 811 .

Zeng R, Zhou ZW, Wu CF, Zhou YL (2008). Reversal effect of aloe emodin liposomes on cisplatin resistance line A549/ DDP human lung adenocarcinoma cells. Zhongguo Zhong Yao Za Zhi, 33, 1443-5. 